\title{
CASE REPORT: PRESENCE OF A DILATED COMMUNICATING VEIN BETWEEN LEFT RENAL AND LEFT ASCENDING, LUMBER VEIN
}

Arindom Banerjee, Anirban Das Gupta, Y. Srinivas Rao, I. Anil Kumar, P. Jhansi Lakshmi

1. Associate Professor. Department of Anatomy, Konaseema Institute of Medical Sciences and Research Foundation, Amalapuram, Andhra-Pradesh, India.

2. Associate Professor. Department of Anatomy, Konaseema Institute of Medical Sciences and Research Foundation, Amalapuram, Andhra-Pradesh, India.

3. Assistant Professor. Department of Anatomy, Konaseema Institute of Medical Sciences and Research Foundation, Amalapuram, Andhra-Pradesh, India.

4. Assistant Professor. Department of Anatomy, Konaseema Institute of Medical Sciences and Research Foundation, Amalapuram, Andhra-Pradesh, India.

5. Tutor. Department of Anatomy, Konaseema Institute of Medical Sciences and Research Foundation, Amalapuram, Andhra-Pradesh, India.

\section{CORRESPONDING AUTHOR}

Dr. Arindom Banerjee,

Associate Professor, Department Of Anatomy,

Konaseema Institute of Medical Sciences and Research Foundation, Amalapuram,

Andhra-Pradesh, India. Pin - 533201.

E-mail: arindomdoc@yahoo.co.in

Ph: 00919966275513

ABSTRACT: Venous anomalies are commonly observed throughout the body during routine dissections or intra-operatively, but a communication between the left renal vein and the ascending lumbar vein has rarely been reported. In this case study a dilated communicating vein was observed connecting the left renal vein with the left ascending lumbar vein. The dilatation may be due to any obstruction in the left renal or inferior vena cava leading to incompetency of the venous valves and retrograde flow of blood causing varicosity in this communicating vein. The rest of the azygos venous system was normal on both sides. Though individuals having this dilated anomalous communication may be asymptomatic, nonetheless awareness regarding this communicating vein is of utmost importance for surgeons performing aorto-iliac and other retroperitoneal surgeries. It may also be confused with other pathologies like para-aortic lymphadenopathy, adrenal pseudo-mass etc. leading to difficulty in radiological diagnosis. Therefore information regarding the presence of this vein is of importance for radiologists and surgeons to avoid pre and post-operative complications.

KEYWORDS :( dilated communicating vein), (ascending lumbar vein), (retroperitoneal surgeries), (para-aortic lymphadenopathy)

INTRODUCTION: Venous system of our body has numerous communicating channels which act as important collateral pathways in case of venous obstructions.There are also various anatomic variants to these venous connections which may create confusing radiological appearances and cause difficulties in surgical procedures.

A dilated communicating vein between the left renal vein and the left ascending lumbar vein is one of them regarding which there have been only a few cases reported in literature.

Varicose veins are dilated and tortuous veins which result from the incompetency of their valves resulting in retrograde flow of blood in them. These are commonly associated with superficial veins of the lower limb and with pathologies of the porto-systemic venous system. 
However its occurrence in the retroperitoneal venous communications is rare. More over a dilated communicating vein between left renal and left ascending lumbar vein has been described as a potential diagnostic pitfall on abdominal computed tomography (CT) because these may mimic para-aortic lymphadenopathy1, 2 . A full understanding of these retroperitoneal structures is also essential for retroperitoneal operations, and the surgeon should thus be informed of the presence of a dilated communicating vein, so that inadvertent bleeding can be avoided.

CASE REPORT: The present case was observed during abdomen dissection in an adult female cadaver for undergraduates in the Department of Anatomy, Konaseema Institute of Medical Sciences and Research foundation, Amalapuram. The left renal vein was seen to drain normally in the inferior vena cava. Left supra-renal vein and left gonadal vein were also seen draining normally into the left renal vein. But the lumbar azygos vein was absent (though present on the right side) and a dilated communicating vein (of almost equal thickness as the left renal vein) was seen to pass deep to the left psoas major muscle into the left para-vertebral gutter and communicate with the left ascending lumbar vein (figure $1 \& 2$ ). This communicating vein formed a loop along the left side of the $2^{\text {nd }}$ and $3^{\text {rd }}$ lumbar vertebrae and ended by joining with the left ascending lumbar vein in front of the transverse process of $3^{\text {rd }}$ lumbar vertebra. The lumbar vein then ascended upwards in the thorax and joined with the left subcostal vein to continue further up as the accessory hemiazygos vein (figure 3). During its course the ascending lumbar vein received communicating branches from the internal vertebral venous plexus and dorsal lumbar veins. The azygos venous system of the right side showed normal anatomical pattern.

DISCUSSION: The ascending lumbar veins are paired and connect the common iliac vein, four pairs of lumbar veins, and ilio-lumbar veins. They ascend deep to the psoas major muscle anterior to the medial portions of the lumbar transverse processes to join with the subcostal veins, which drain into the azygos vein on the right and the hemi-azygos vein on the left, respectively.

Embryogenesis of IVC, renal veins and the azygos venous system is complex process of successive appearance of three pairs of primitive veins (posterior cardinal, sub-cardinal and supra-cardinal veins) interconnecting, anastomosing and followed by regression. The subcardinal and supra-cardinal veins form a vascular ring around the aorta with several transverse anastomotic channels ${ }^{3}$. The LRV is usually formed from the transverse anastomotic vessel between the left and right sub-cardinal veins and the supra-cardinal veins along with the azygos venous line (which develops subsequently) gives rise to the azygos venous system including the ascending lumbar vein. Variations in the development of the veins give rise to conditions like double IVC, circum-aortic renal vein, post-caval ureter etc.

The communicating vein is probably due to remnant of a transverse anastomotic channel between the left sub-cardinal vein and the supra-cardinal vein ${ }^{4}$ (figure 4).

The incidence of the communicating vein between the LRV and the ascending lumbar/ hemiazygos venous system is approximately $90 \%$ in anatomic dissections ${ }^{4,5}$ and between $69 \%$ $91.5 \%$ in reported autopsy studies ${ }^{6}$. On phlebographic studies, the incidence of this normal venous communication has been variably found to be between $34 \%-75 \%{ }^{7}$, whereas the incidence on CT scan is around 35\%. Varicosity of this venous communication has been 


\section{CASE REPORT}

reported in $9 \%$ of the patients on phlebographic studies ${ }^{7}$, first of which was by Lein et al 1 (graph1).

The exact cause of this dilatation is not clear but can be attributed to the increased renal venous pressure due to some pathological conditions like renal vein thrombosis or postoperative renal ligation ${ }^{2,8}$. It may also result from obstructive lesions in the inferior vena cava causing retrograde venous flow and subsequent dilatation of the communicating vein.

As mentioned in Gray's anatomy ${ }^{9}$ the ascending lumbar vein is usually joined by a small vessel from the back of inferior vena cava or left renal vein on the left and this vein represents the azygos line and hence is termed as the lumbar azygos vein. In the present case because the lumbar azygos vein is absent on the left side, this communicating channel between the left renal vein and the left ascending lumbar vein might be considered as a dilated lumbar azygos vein though following an abnormal looped course before connecting with the left ascending lumbar vein.

CONCLUSION: Whether we consider this as a dilated communicating vein or a dilated left lumbar azygos vein is open for discussion but the identification of this entity is very important because it may mimic normal and pathological structures that are located in close proximity to the left renal hilum and para-vertebral structures. Awareness regarding this communicating vein is of utmost importance for surgeons performing aorto-iliac and other retroperitoneal surgeries as it may cause life threatening retro-peritoneal hemorrhage.

During radiological studies also this should not be confused with other pathological entities like enlarged para-aortic lymph nodes which are affected due to metastases from various malignancies like testicular carcinomas.

Therefore to conclude a dilated communicating vein between the left renal vein and the left ascending lumbar vein is a rare anatomical variation which should be studied in detail to avoid any radiological misinterpretations and operative complications.

ACKNOWLEDGEMENT: The authors would like to thank Dr. P.C. Maharana, Professor and Head of the Department of Anatomy, KIMS \& RF, Amalapuram, for his valuable advice and guidance in giving the final shape to this manuscript.

\section{REFERENCES:}

1. Lien HH, von Krogh J. Varicosity of the left renal ascending lumbar communicating vein: a pitfall in CTdiagnosis. Radiology.1984; 152:484.

2. Meanock CI, Ward CS, Williams MP. The left ascending lumbar vein: a potential pitfall in CT diagnosis. ClinRadiol.1988; 39:565-66.

3. Sato T, Sato K. Regional anatomy for operative surgery of genitourinary organs: Inferior vena cava and left renal vein. RinshoHinyokika.1988; 42: 1063-74.

4. Yao Y, Okada Y, Yamato M, Ohtomo K. Communicating vein between the left renal vein and left ascending lumbar vein: incidence and significance on abdominal CT. Radiat Med.2003; 21: 252-7.

5. Hoeltl W, Aharinejad S. Renal vein anatomy and its implication for retroperitoneal surgery. J Urol.1990; 143:1108-14.

6. Pick JW, Anson BJ. The renal vascular pedicle: An anatomical study of 430 body halves. J Urol. 1940; 44: 411-34. 
7. Lein HH, Kolbonsvedt A. Phlebographic appearance of the left renal and left testicular vein. ActaradiolDiagn. 1977; 18:321-32.

8. Jakhere SG, Yadav DA, Tuplondhe GR. Case report: Varicosity of the communicating vein between the left renal vein and the left ascending lumbar vein mimicking a renal artery aneurysm: report of an unusual site of varicose vein and a novel hypothesis to explain its association with abdominal pain. Indian J Radiol Imaging. 2011; 21(1):24-7.

9. Standring S. Gray's Anatomy. The Anatomical Basis of Clinical Practice. 40 th edition. Elsevier Churchill Livingstone; 2008.pp-1075.

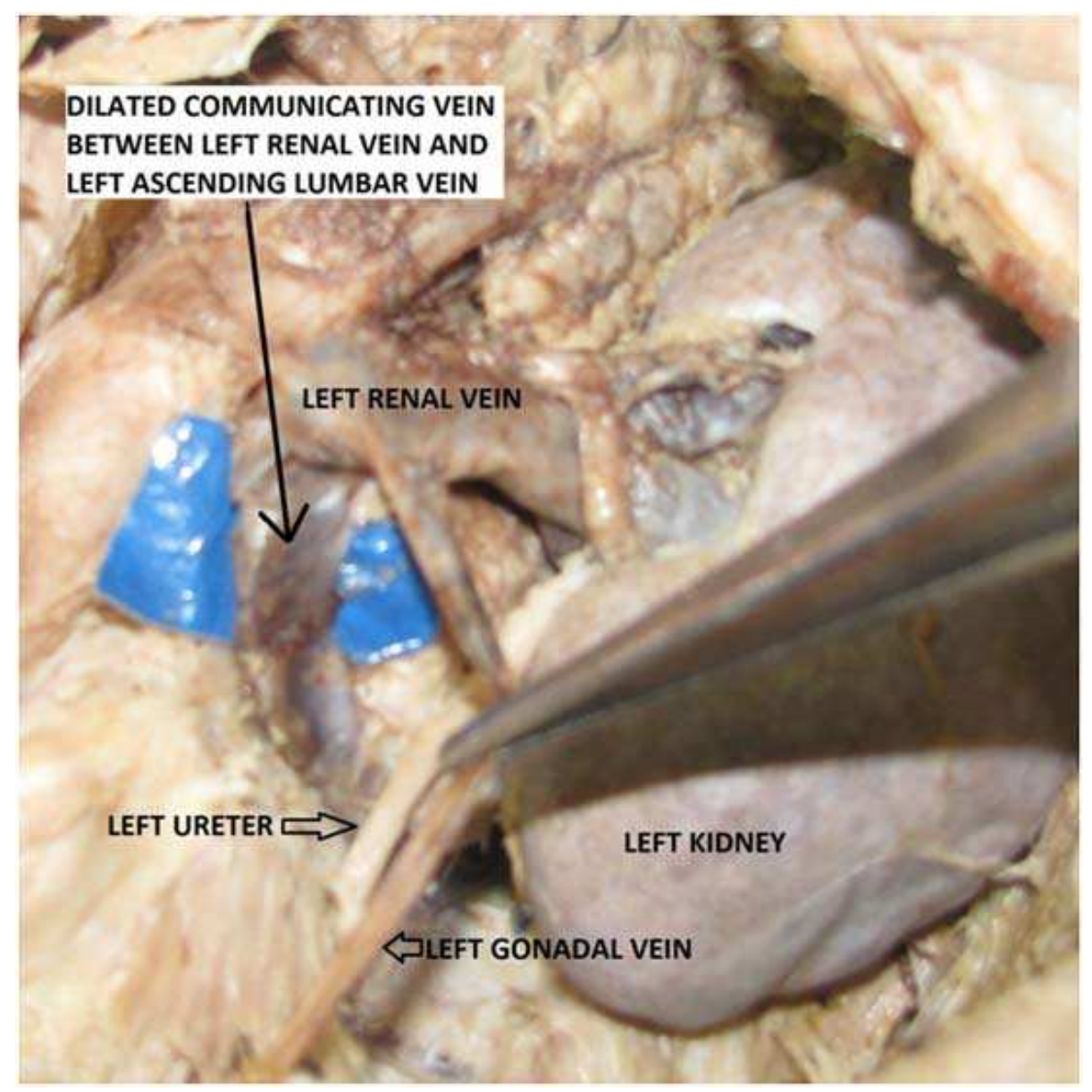

Figure1. Showing the dilated communicating vein (of almost equal size) connected to the left renal vein. The left gonadal vein is held by forceps and the left ureter can also be seen 


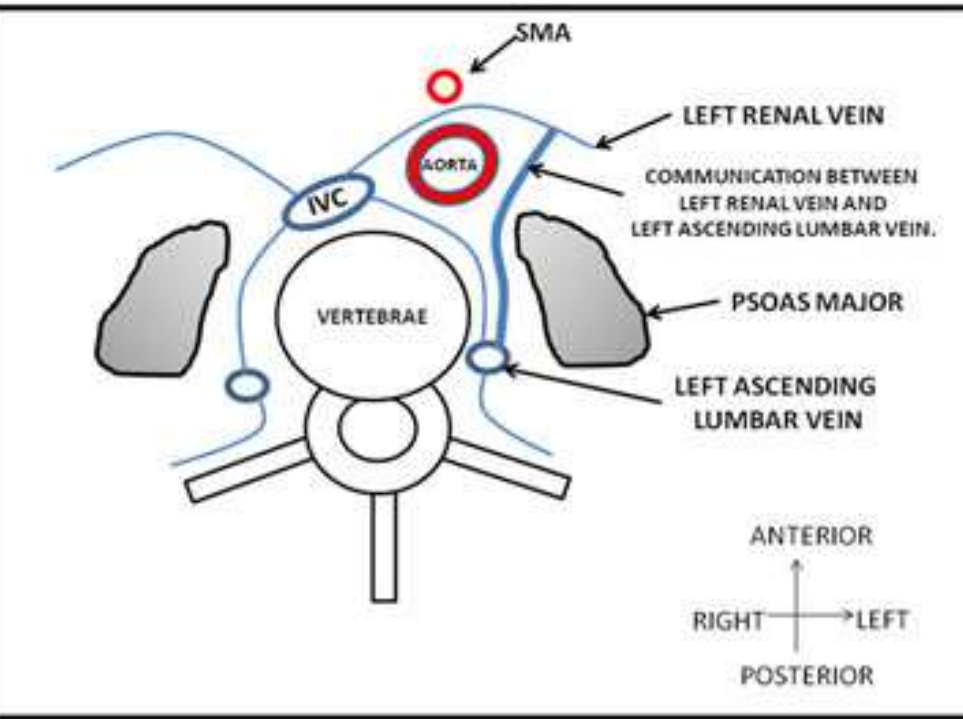

Figure 2.schematic diagram to show communication between left renal vein and left ascending lumbar vein.

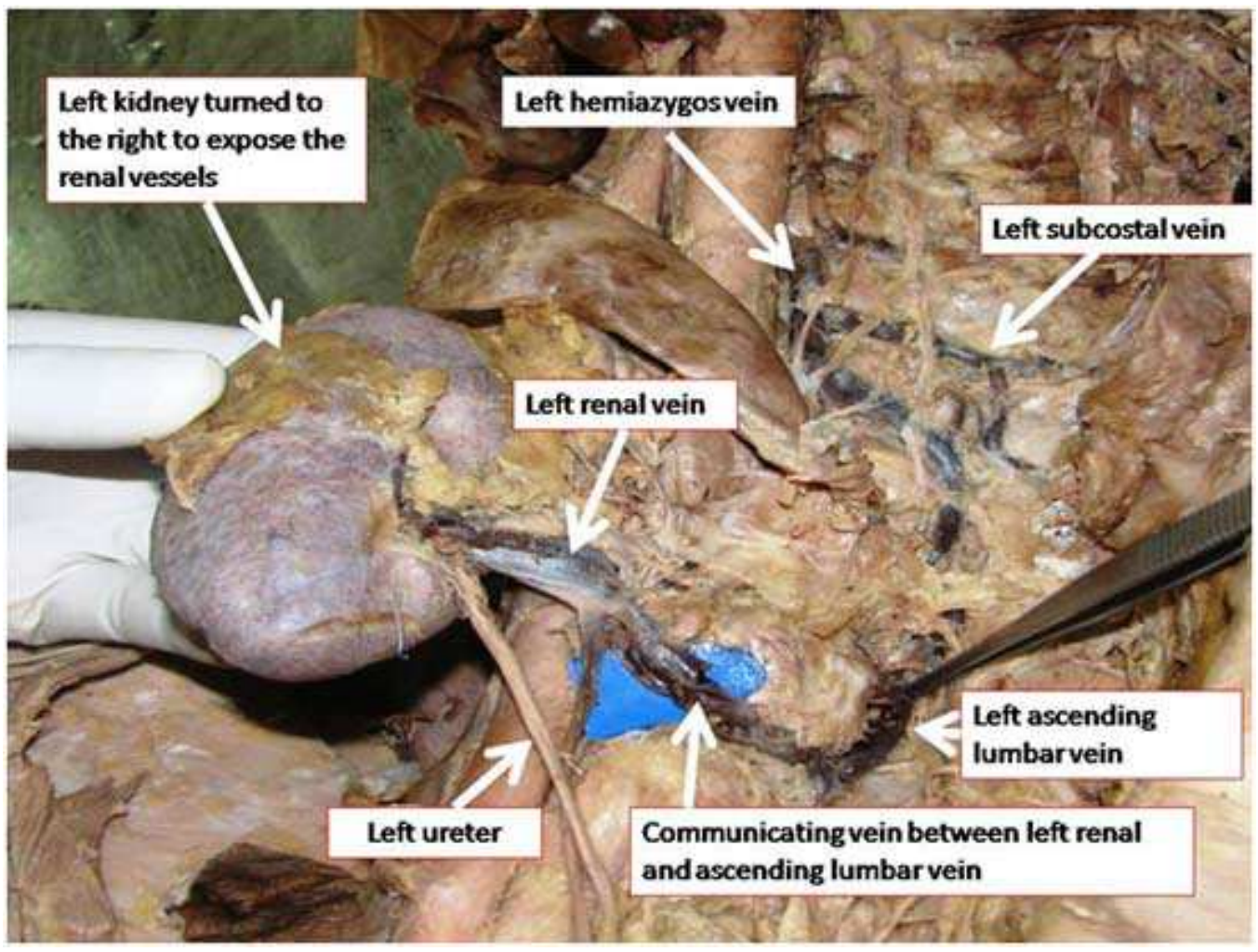

Figure3. Showing the dilated vein which connects the left renal vein and the left ascending lumbar vein. The left kidney is turned towards the right side for clarity. 


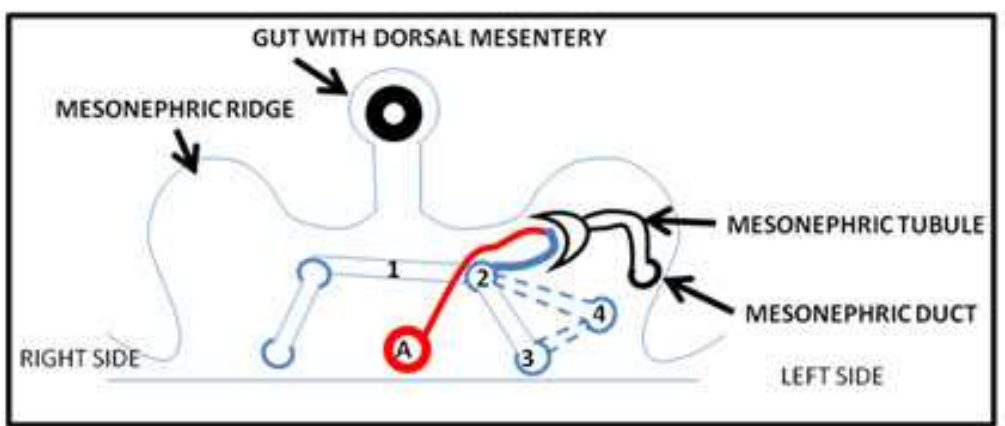

Figure 4.Schematic drawing of early developmental process of the venous system. The Left renal vein is formed from the transverse anastomotic vessel (1) between the left and right subcardinal veins (2). The supracardinal veins (3) develop into the azygos and hemiazygos vein. The caudal cardinal Veins (4) almost disappear in the later developmental course. A=AORTA

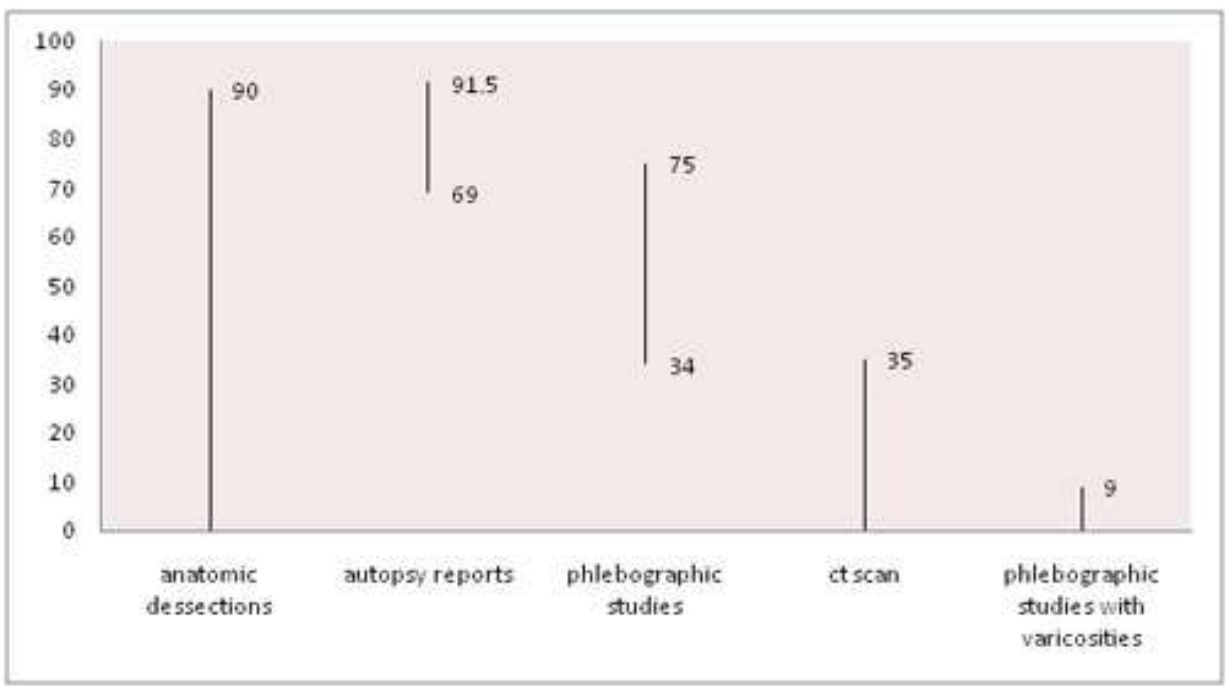

Graph 1 showing the incidence of normal communicating vein (in percentage) during various procedures. Also note the incidence of varicose communicating vein (9\%) in phlebographic studies. 